a three month period in response to daily, weekly and monthly question sets (table 1). An optional diary component was included, but not integrated into the EPR. The ePROS had been determined during earlier interviews with rheumatology patients, practitioners and researchers.

Qualitative interviews were conducted with patients at the end of the three month period. Interviews explored patients' views on the components of the app, and perceived implications for self-management and clinical care. Interviews were transcribed and analysed thematically.

Results: Qualitative analysis of the data identified a number of themes including; the benefits and limitations of using scales to reflect changes in symptoms experienced, the value of the diary for providing contextual information and an "outlet" for feelings, and the impact the data made to their clinical consultation and self-management.

Overall, the collection of longitudinal data was seen as useful by patients. Successful integration with the EPR allowed data to be displayed graphically during clinical consultations. Reviewing remote monitoring data detected changes which may otherwise have been missed such as flares in disease, or gradual improvements in response to new treatments. Data therefore facilitated "a shared conversation" and decision making around treatment plans.

Additionally, being able to self-reflect on data recorded enabled patients to identify triggers and alleviators in relation to their disease activity and take steps to self-manage their RA; for example, by recognising when they needed to rest as opposed to "just carrying on" when their symptoms were more severe.

\begin{tabular}{ll} 
Table 1. ePROS \\
\hline Daily & $\begin{array}{l}\text { Pain, difficulty with physical activities, fatigue, sleep difficulties, physical wellbeing, } \\
\text { emotional wellbeing, coping } \\
\text { Morning stiffness }\end{array}$ \\
Weekly & $\begin{array}{l}\text { Number of tender \& swollen joints } \\
\text { Global assessment of wellbeing } \\
\text { Employment status } \\
\text { Impact on number of hours worked } \\
\text { Experienced a flare }\end{array}$ \\
Description of flare \\
Monthly
\end{tabular}

Conclusions: The app was well received by patients and feedback suggests that the ePROS recorded can capture changes in disease activity in a manner that is meaningful to patients and facilitates both clinical consultations and self-management.

References:

[1] http://oml.eular.org/Toolbox of Patient Reported Outcomes.

Acknowledgements:.

Disclosure of Interest: None declared

DOI: 10.1136/annrheumdis-2017-eular.6552

\section{AB1098 TEMPORARY WORK DISABILITY CAUSED BY MUSCULOSKELETAL DISEASES AT THE HOSPITAL CLÍNICO UNIVERSITARIO DE VALLADOLID: 6 MONTHS EXPERIENCE}

M.D. Sánchez González ${ }^{1}$, C.C. Macía Villa ${ }^{2}$, C. González-Montagut Gómez ${ }^{1}$ J. Medina Luezas ${ }^{1} .{ }^{1}$ Rheumatology, Hospital Clínico Universitario de Valladolid, Valladolid; ${ }^{2}$ Rheumatology, Hospital Universitario Severo Ochoa, Leganés (Madrid), Spain

Background: Musculoskeletal diseases are the leading cause of disability in the world and have a high impact on direct (health) and indirect (labor) costs. Labor casualties in Spain, when temporary, are known as temporary work disability (TWD). Since 2013, follow-up of patients with TWD (when the origin of the disease is a musculoskeletal condition) is being carried out in a monographic consultation within the external consultations of the Rheumatology Service of the Hospital Clínico Universitario de Valladolid.

Objectives: To describe the experience of the last 6 months in the consultation of temporary musculoskeletal incapacities (TWDMSDs) of the Hospital Clínico Universitario de Valladolid.

Methods: The TWDMSDs consultation is operational 2 days a week. The referral system is direct from Medical Inspection via email (1st part confirmatory work leave). The patients come from 7 Health Centers (population 82,000 people). The agenda is configured daily according to the emails sent, contacting the patients by telephone, excluding those with trauma, surgeries, pregnancies, non-localized, rejection or discharge. The assessment of the patients in consultation, according to usual clinical practice. A medical report is issued (medical history, physical examination, completed or requested tests, recommendations and treatment). The data are collected in SPSS, proceeding to its subsequent analysis.

Results: During the last six months of follow-up, 354 emails have been received. A total of 106 patients were evaluated, with the following characteristics: $54.3 \%$ women and $45.7 \%$ men, mean age 43.4 years, 95\% performed physical work. Axial pathology was observed in $67.8 \%$ of cases and peripheral in $32.2 \%$. The patients evaluated with some rheumatic pathology reached $96 \%$. The average delay from the start of the work leave to the email was 12.2 days, and from the start of the work leave to the first consultation of 6.7 days (including weekends). $65.4 \%$ of the patients were discharged from the TWDMSDs agenda in the 1st consultation, without requiring interconsultations or requests for diagnostic tests, with an infiltration of $8 \%$ of the patients, arthrocentesis at $2 \%$, ultrasound at $28 \%$ and Exercise guidelines were given to $76 \%$ of patients. The mean number of consultations up to discharge was 1.3. The mean time from onset of discharge to discharge was 21.1 days and from the first consultation until discharge by Rheumatology was 6.6 days.

Conclusions: The TWDMSDs consultation makes possible the early detection of rheumatologic musculoskeletal pathology, allowing an early action that minimizes the number of requested tests and interconsults generated and achieves an early diagnosis and treatment of patients, with the consequent benefits that this entails. The patients evaluated in consultation are mainly of average age, with physical work, mechanical pathology, resolution of the problem that causes the TWD and reincorporation to the working life of early form. In the discharge report, recommendations are included to minimize future casualties (work refocus, orthotics, exercises, treatment regimens in the event of a recurrence of symptoms) and explain the importance of being actively involved in their pathology to prevent progression. Disclosure of Interest: None declared

DOI: 10.1136/annrheumdis-2017-eular.2886

\section{AB1099 COUNSELLING ON FAMILY PLANNING AND CONTRACEPTION, AND PREGNANCY OUTCOME IN WOMEN WITH RHEUMATIC DISEASES: A NATIONAL SURVEY OF 398 PATIENT-REPORTED QUESTIONNAIRES FROM 24 RHEUMATOLOGY CENTERS}

M.G. Lazzaroni ${ }^{1}$, F. Dall'Ara ${ }^{1}$, L. Andreoli ${ }^{1}$, C. Carini ${ }^{1}$, M. Rodrigues ${ }^{2}$, R. Reggia ${ }^{1}$, E. Bartoloni-Bocci ${ }^{3}$, R. Gerli ${ }^{3}$, C.B. Chighizola ${ }^{4}$, M. Gerosa ${ }^{4}$ P.L. Meroni ${ }^{4}$, L. Sinigaglia ${ }^{4}$, P. Conigliaro ${ }^{5}$, R. Perricone ${ }^{5}$, A. Corrado ${ }^{6}$, F.P. Cantatore ${ }^{6}$, S. D'Angelo ${ }^{7}$, I. Olivieri ${ }^{7}$, M. Favaro ${ }^{8}$, A. Doria ${ }^{8}$, A. Ruffatti ${ }^{8}$, E. Generali ${ }^{4}$, C. Selmi ${ }^{4}$, M. Meroni ${ }^{9}$, M. Cutolo ${ }^{9}$, M. Padovan ${ }^{10}$, M. Govoni ${ }^{10}$ G. Pazzola ${ }^{11}$, C. Salvarani ${ }^{11}$, S. Peccatori ${ }^{12}$, G. Paolazzi ${ }^{12}$, I. Prevete ${ }^{5}$, G.D. Sebastiani ${ }^{5}$, G. Minisola ${ }^{5}$, A. Brucato ${ }^{13}$, V. Ramoni ${ }^{14}$, R. Caporali ${ }^{14}$ C. Montecucco ${ }^{14}$, C. Tani ${ }^{15}$, M. Mosca ${ }^{15}$, M. Trevisani ${ }^{16}$, N. Malavolta ${ }^{16}$, M. Vadacca ${ }^{5}$, A. Afeltra ${ }^{5}$, E. Vivaldelli ${ }^{17}$, A. Maier ${ }^{17}$, E. Baldissera ${ }^{4}$, E. Visalli ${ }^{18}$, R. Foti ${ }^{18}$, L. Zuliani ${ }^{19}$, A. Gabrielli ${ }^{19}$, N. Romeo ${ }^{20}$, A. Tincani ${ }^{1}$. ${ }^{1}$ Brescia, Italy; ${ }^{2}$ Coimbra, Portugal; ${ }^{3}$ Perugia; ${ }^{4}$ Milano; ${ }^{5}$ Roma; ${ }^{6}$ Foggia; ${ }^{7}$ Potenza; ${ }^{8}$ Padova;

${ }^{9}$ Genova; ${ }^{10}$ Ferrara; ${ }^{11}$ Reggio-Emilia; ${ }^{12}$ Trento; ${ }^{13}$ Bergamo; ${ }^{14}$ Pavia; ${ }^{15}$ Pisa; ${ }^{16}$ Bologna; ${ }^{17}$ Bolzano; ${ }^{18}$ Catania; ${ }^{19}$ Ancona; ${ }^{20}$ Cuneo, Italy

Background: Rheumatic diseases (RD) predominantly affect young women during reproductive age. Pregnancy, contraception and family planning (FP) are crucial for the quality of life of these patients.

Objectives: We aimed to investigate 'women's health' through a self-reported questionnaire. Answers from patients with connective tissue diseases (CTD) vs chronic arthritis (CA) were compared.

Methods: 24 centres distributed the questionnaire $(65$ multiple-choice and 12 open-answer questions) to women with $\mathrm{RD}$ (18-45years) regularly attending their outpatient clinics.

Results: Answers were collected from 249 CTD vs 149 CA patients. Their desire to have children was influenced by RD in $40 \%$ of cases: half of them reduced the number of children they wanted (Table 1). $39 \%$ CA vs $29 \%$ CTD were afraid of being mother because of disability.

$24 \%$ CTD vs. $18 \%$ CA had at least one miscarriage; $21 \%$ CTD vs. $2 \%$ CA had more than one.

$31 \%$ CTD and $34 \%$ CA were never asked about their desire to have children. $61 \%$ CTD vs $70 \%$ CA received counselling about contraception, given by a gynaecologist $(\mathrm{G})(58 \%$ vs $64 \%)$, rheumatologist $(\mathrm{R})(22 \%$ vs $14 \%)$ or both $(7 \%$ vs $9 \%$ ). $60 \%$ in both groups received a counselling before pregnancy: $34 \%$ vs $39 \%$ from $\mathrm{R}$ and $\mathrm{G}, 14 \%$ vs $22 \%$ by $\mathrm{R}$. This positively changed family planning in $64 \%$ vs $59 \%$. We created a Knowledge Index (based on the average of the normalized performed scores on 6 key questions for different sections): $55 \%$ CTD patients vs $44 \%$ CA had a medium-high score. A higher score directly correlated with the desire to became pregnant and with a multidisciplinary counselling.

The disease has reduced your desire to have children?
\begin{tabular}{|l|c|c|}
\hline & CTD & CA \\
\hline NO & $36 / 91(40 \%)$ & $22 / 54(41 \%)$ \\
\hline YES & $52 / 91(57 \%)$ & $28 / 54(52 \%)$ \\
\hline No Answer & $3 / 91(3 \%)$ & $4 / 54(7 \%)$ \\
\hline $\begin{array}{c}\text { If yes, I reduced the number of } \\
\text { children that I wanted, because I } \\
\text { was afraid... }\end{array}$ & CTD & CA \\
\hline $\begin{array}{c}\text { C..of not being able to take care of } \\
\text { them because of the disease }\end{array}$ & $26 / 91(29 \%)$ & $21 / 54(39 \%)$ \\
\hline $\begin{array}{c}\text {...that the child could have the same } \\
\text { disease }\end{array}$ & $15 / 91(17 \%)$ & $8 / 54(15 \%)$ \\
\hline $\begin{array}{c}\text {...that drugs or disease could harm } \\
\text { the baby }\end{array}$ & $26 / 91(29 \%)$ & $20 / 54(37 \%)$ \\
\hline
\end{tabular}

Table 1. Reasons for reduced family size in patients who declared that their RD had influenced their desire of having children 